\section{EL BICITAXISMO EN BOGOTÁ: APROXIMACIONES A LA CONSTITUCIONALIZACIÓN DEL CONTRATO DE TRANSPORTE, A PARTIR DE UNA CUESTIÓN PRÁCTICA*}

\author{
RICKSHAW IN BOGOTA: APPROXIMATION \\ FROM A PRACTICAL MATTER TO THE \\ CONSTITUTIONALIZATION OF THE \\ TRANSPORTATION CONTRACT
}
O BICITAXISMO EM BOGOTÁ: ABORDAGENS PARA A CONSTITUCIONALIZACCÃO DO CONTRATO DE TRANSPORTE, DESDE UMA QUESTÂO PRÁTICA

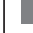

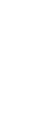
Luz Mary Rincón Romero ${ }^{\text {a }}$
luzmaryrinconromero@yahoo.es Fecha de recepción: 23 de Mayo 2014 Fecha de revisión:21 de Julio 2014 Fecha de aceptación: 25 de Julio 2014

\section{RESUMEN}

Con la entrada en vigencia del paradigma de la democracia constitucional, la Constitución ha venido a entenderse como un "sistema de reglas, sustanciales y formales" ${ }^{1}$ dirigida a todos los centros de poder, cuyo principal objetivo es establecer un límite a la forma como este se ejercita. Como consecuencia de lo anterior, incluso las relaciones entre los particulares deben dirigirse teniendo como margen de desarrollo los derechos fundamentales, esencia y sustrato de todo Estado que se aprecie de denominarse "social de Derecho". Por ello, si se atiende a que esas relaciones se desarrollan normalmente a través de los contratos, habrá que llevar la mirada hacia los mismos, para contribuir en la comprensión constitucional de los diversos tipos negóciales.

\footnotetext{
* Articulo de reflexión

a. Luz Mary Rincón, abogada, Universidad Libre de Colombia; especialista en Derecho Contractual y Tributario, Universidad Colegio Mayor de Nuestra Señora del Rosario; magíster en Derecho Penal y Criminología; catedrática, Universidad Colegio Mayor de Cundinamarca. Correo electrónico: luzmaryrincon@yahoo.es, teléfono: 316-6284615.

1 FERRAJOLI, Luigi. Democracia y garantismo. Edición de Miguel Carbonell. Pág. 32. Editorial Trotta. Madrid, 2008.
}

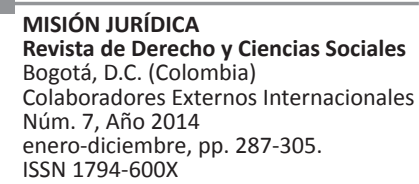


Es precisamente bajo los lineamientos del objetivo referido que se orienta el presente artículo. Se somete a estudio el contrato de transporte, concretándose su análisis en los conceptos que la doctrina, la ley y la jurisprudencia han brindado de él, específicamente en su modalidad de transporte terrestre.

\section{PALABRAS CLAVES}

"Bicitaxi",

Contrato,

Transporte, Responsabilidad Civil, Derechos Fundamentales, Constitución.

\section{ABSTRACT}

With the entry into force of the paradigm of Constitutional Democracy, the Constitution should be understood as a "system of rules, substantive and formal" addressed to all centers of power and which its main objective is to establish a limit on how this is put into practice. Therefore it is clear that even the relationships between individuals should be managed under the frame of development, taking Fundamental Rights that are the essence of any State under the "Rule of Law". These relationships are usually developed through contracts then, on this article, we will take a closer look on them to help in the constitutional understanding of the various negotiable types.

It is precisely the target under the previously referred guidelines where this article aims. To study the transportation contracts materializing this analysis on the concept that doctrine, law and jurisprudence has provided for it, specifically in land transportation mode.

\section{KEYWORDS}

"Rickshaw", Transportation Contract, Civil Liability, Fundamental Rights, Constitution.

\section{RESUMO}

Com a entrada em vigor do paradigma da democracia constitucional, a Constituição passou a ser entendida como um "sistema de regras, materiais e formais", destinada à todos os centros de poder, cujo principal objetivo é estabelecer um limite para quanto é exercido. Como resultado do exposto acima, incluindo as relações entre os indivíduos devem ser tratados como tendo possibilidades de desenvolvimento os direitos fundamentais, a essência eo substrato de qualquer Estado a ser chamado de "Social de Direito". Portanto, se essas relações são normalmente desenvolvidas por meio de contratos, temos de olhar para trazê-los a contribuir para a compreensão desde a Constituição dos diferentes tipos negociáveis.

É precisamente sob as diretrizes desse objectivo que o presente artigo é dirigido. $O$ contrato de transporte e estudado, especificando a sua análise sobre os conceitos que a doutrina, legislação e jurisprudência forneceram, especificamente sob a forma de transporte terrestre.

\section{PALAVRAS-CHAVE}

"Bicitaxi", contrato, transporte, responsabilidade civil, direitos fundamentais, Constituição.

\section{INTRODUCCIÓN}

El incremento demográfico, el aumento de la población y el crecimiento del perímetro urbano (atado al desarrollo de las ciudades como consecuencia de fenómenos como el desplazamiento, la industrialización y la globalización), definen las variaciones con tendencia al alza que ha tenido la demanda del transporte urbano en la ciudad de Bogotá y, en general, en las ciudades capitales y principales de los países en vía de desarrollo.

No obstante los diversos esfuerzos hechos por los gobiernos - tanto nacionales como locales -, por facilitar la movilidad en las ciudades y garantizar, para el caso colombiano, lo expuesto en el artículo 24 de la Constitución, referente a la libertad de locomoción y domicilio, éstos no han sido suficientes; por el contrario, la situación de movilidad viene en deterioro, ocasionando congestión vehicular y malestar por parte de la población. La desesperación se incrementa ante la situación de incomodidad en los sistemas de transporte masivo, como los metros y vehículos articulados y biarticulados. Aunado a lo anterior, están las dificultades de acceso de los habitantes al sistema público de transporte, como consecuencia del deterioro en la malla vial o la falta de pavimentación, como ocurre en algunas áreas de la ciudad de Bogotá, lo que impide el ingreso de los vehículos para el transporte, desde las grandes terminales o estaciones, hasta los lugares de residencia.

Por esta situación, y buscando facilitar el desplazamiento de los ciudadanos hacia sus 
domicilios o hacia los portales del sistema de transporte masivo "Transmilenio", en Bogotá se han venido desarrollando medios de transporte no convencionales, que muchas veces escapan a la regulación que se encuentra en el ordenamiento jurídico colombiano. Esto crea incertidumbre acerca de cuál es el tratamiento que se le debe dar a este servicio, los principios que lo regulan, los mecanismos para dirimir controversias en torno a problemáticas surgidas por el uso y operación de estos medios $y$, especialmente, acerca de cuestiones jurídicas tan importantes como la naturaleza jurídica del acuerdo que celebran usuario y conductor. Por lo tanto es necesario preguntarse sobre la existencia, o no, de un contrato de transporte, el tipo de responsabilidad que se derivaría con ocasión de los daños que un "pasajero" de este medio pueda llegar a recibir en desarrollo del contrato de transporte celebrado, la posibilidad del aseguramiento de dicha actividad, y su control, vigilancia y restricción por parte del Estado; por encontrarse en discusión la seguridad de las personas que son transportadas por estos medios de transporte.

Uno de los medios de transporte no convencionales a los que se hace referencia, y de mayor uso por parte de los ciudadanos de Bogotá, es el "bicitaxi" o "tricimóvil", este último definido por la ley 769 del 06 de agosto de 2002-Código Nacional Terrestre, como: "Vehículo no motorizado de 3 ruedas, accionado con el esfuerzo del conductor, por medio de pedales"2; la doctrina lo define como "un vehículo para el transporte especializado de pasajeros, constituido bajo el principio de la bicicleta, accionado con tracción humana, con una capacidad de traslado de dos pasajeros adultos sentados y su conductor (...), proviene del japonés jinrikisha, un cochecito ligero, de dos ruedas, abierto o cerrado, pero arrastrado por una persona, que va a pie o en una especie de bicicleta"3.

Si bien tal medio no es una innovación propia de Bogotá, pues es empleado en ciudades de la importancia y desarrollo como Barcelona, Berlín, Múnich, Copenhague, Londres y Washington, la situación jurídica que se presenta en torno a él,

2 Artículo 2 Ley 769 de 2002 "Por la cual se expide el Código Nacional de Tránsito Terrestre y se dictan otras disposiciones"

3 CONCEJO DE BOGOTÁ, Proyecto de Acuerdo No. 396 de 2007 "Por el cual se dictan disposiciones relativas a la actividad de los tricimóviles con respecto al tránsito dentro del Distrito Capital". sí es especial y problemática, pues, a pesar de su importancia para la movilidad y transporte de la ciudad, esta actividad no se encuentra regulada y, hasta hace tres (3) años, se encontraba, prácticamente, proscrita por el ordenamiento jurídico.

La laguna o vacío jurídico existente ha tenido dos causas que merecen ser referidas: la decidía e indiferencia de la administración distrital para regular este medio de transporte y las diversas disputas hermenéuticas existentes respecto de la admisibilidad, o no, de esta forma de transporte terrestre. Respecto de la primera, la Secretaria de Movilidad ha declarado en diversas ocasiones, ante los medios de comunicación, que cuestiones de seguridad, de orden público, de garantía de los derechos de los pasajeros y de los propios conductores $\mathrm{y}$, especialmente, de incompetencia jurídica, llevan a que la Administración Distrital no pueda expedir un acto administrativo que regule la materia, pues tal función le es inherente al Ministerio de Transporte ${ }^{4}$.

Por otra parte, está la discusión interpretativa en torno a dos interrogantes: en primer lugar, si es válido, a la luz del ordenamiento jurídico, el transporte terrestre por medios no motorizados, como lo son los "tricimóviles" y, en segundo lugar, cuál es la autoridad gubernamental llamada a reglamentar esta actividad; que fuera de cualquier discusión, es un servicio público.

Es en estos dos últimos tópicos, sobre los cuales se extenderá la temática del presente artículo; se pretende, a partir de la descripción de la normatividad que versa sobre la materia, como la ley 105 de 1993, con la cual se dictan disposiciones básicas sobre transporte y se reglamenta la planeación en el sector del transporte; la ley 336 de 1996 , por la cual se adopta el estatuto nacional de transporte; la ley 769 de 2002, por la cual se expide el código nacional de tránsito, y la ley 1383 de 2010, la cual reformó el código de tránsito, dirimir la controversia en la discusión sobre si esta forma de transporte está prohibida o no. Para ello la sentencia C-981 de 2010, proferida por la Corte Constitucional, es un valioso aporte práctico para soportar la conclusión de este trabajo; la cual será

4 Entrevista a la Subsecretaria de Servicios de Movilidad, Ángela Arenas. Recuperado el 30 de septiembre de 2013 de: http://e. eltiempo.com/media/produccion/bicitaxis/index.html 
determinar los derechos fundamentales de los sujetos que intervienen en la relación bicitaxista - Estado - usuario y analizar el contrato de transporte como servicio público y como relación de derecho privado.

\section{PROBLEMA DE INVESTIGACIÓN}

El margen de delimitación teórica del presente trabajo, está dado por la respuesta a una pregunta principal y tres auxiliares. En cuanto a la primera, el planteamiento fue el siguiente:

1. ¿Debe regularse el contrato de transporte terrestre, a través de bicitaxis, para garantizar los derechos fundamentales de usuarios y de conductores, en la ciudad de Bogotá?

Y respecto de las denominadas auxiliares, su esquematización investigativa, fue:

A. ¿Es el acuerdo de voluntades, entre una persona que hace uso de los servicios de un "bicitaxi" y el conductor de esté un contrato de transporte terrestre, válido y eficaz?

B. ¿Cuál es la naturaleza jurídica de la responsabilidad civil generada como consecuencia de los daños ocasionados a un usuario, en desarrollo de las actividades del bicitaxismo?

C. ¿Qué derechos fundamentales de los conductores y propietarios de bicitaxis se encuentran en peligro de ser vulnerados, al no existir normatividad que regule el transporte, a través de estos medios no motorizados?

\section{METODOLOGÍA}

La metodología utilizada está guiada por los planteamientos de la investigación cualitativa, por cuanto se conceptualiza a partir de una realidad social, observando los fenómenos que se presentan, ante la ausencia de una norma que regule la situación examinada; se busca fundamentar la teoría de llegada, a partir de datos empíricos, entrecruzados con planteamientos doctrinales, legales y jurisprudenciales. Respecto del tipo de investigación, es de carácter sociojurídico, partiendo de una problemática surgida en la ley y reflejada en su ámbito de aplicación; se busca plantear una solución que impacte favorablemente a la población objeto de estudio, así como al ordenamiento jurídico. Finalmente, la forma de esta investigación es exploratoria, descriptiva y documental; lo primero, por la ausencia de estado del arte o antecedentes investigativos en cuanto al objeto de investigación y su entorno; lo segundo, por relatar analíticamente un conjunto de hechos sociales y jurídicos que, interpolados, estructuran el problema de investigación $\mathrm{y}$, por último, es documental, por remitirse a las diversas fuentes del derecho, para hallar el asidero de la solución propuesta.

\section{CONTRATO DE TRANSPORTE}

Se puede afirmar que el contrato de transporte es un convenio por el cual, una persona llamada transportador o transportista se obliga, a cambio de un precio, que se denomina flete o porte, a conducir de un lugar a otro, personas o cosas ${ }^{5}$. Es menester decir, que esta es una definición muy genérica de lo que es el contrato de transporte, ya que solo se limita a dar un concepto en sentido amplio, sin discriminar la forma de transporte; pudiendo ser aéreo, terrestre o marítimo.

El artículo 981 del Código de Comercio, brinda un concepto de lo que es el contrato de transporte, definiéndolo de esta manera; "El transporte es un contrato por medio del cual una de las partes se obliga para con otra, a cambio de un precio, a conducir de un lugar a otro, por determinado medio y en el plazo fijado, personas o cosas y a entregar estas al destinatario".

Como se puede ver, aquella persona que asume esta obligación, contrae una prestación de hacer, debiendo realizar el traslado de un lugar a otro de personas o cosas. Como lo expresa el profesor Arrubla Paucar, este desplazamiento es de contenido material y no jurídico, pues en el transporte de personas, no se traslada ni posesión ni propiedad; sin embargo, existen tratadistas que, además, le han dado el carácter de obligación de resultado, debido que el deber que tiene el transportador o porteador, es el de conducir y entregar. 
En este punto, la Corte Suprema de Justicia, en sentencia de casación civil de $1^{\text {o }}$ de Junio de 2005, se ha expresado de la siguiente manera:

"Tiene definido la jurisprudencia que, en verdad, la del transportador es una obligación de resultado, en la medida en que para cumplirla no le basta simplemente con poner toda su diligencia y cuidado en la conducción de las personas o las cosas, pues con arreglo a dicha preceptiva menester es que la realice en perfectas condiciones, de forma tal, que solo podría eximirse de ello, demostrando la concurrencia de alguno de los acontecimientos que depende de lo que se ha denominado una "causa extraña".

El tratamiento expresado por la Corte y por el cual se ha definido la obligación del transportador como una obligación de resultado, es clara, precisa y se ajusta a los lineamientos legales plasmados por el legislador, en su potestad de configuración legislativa; por ende, esta investigación acoge la tesis de la Corte, entendiendo que todo transportador tiene a su cargo una obligación de resultado y, por lo tanto, debe responder por esta, más allá del tipo o forma en la cual se ejecute la obligación.

Por otra parte, en sentencia del 30 de Noviembre de 2004, la Corte se pronunció acerca del concepto de contrato de transporte, los elementos que lo integran y las partes que en su celebración concurren: "De conformidad con lo que dispone el artículo 981 del Código de Comercio, modificado por el artículo $1^{\circ}$ del Decreto 01 de 1990, el transporte mercantil es un contrato por virtud del cual una de las partes, llamada transportador, transportista o porteador, se obliga con la otra, a cambio de un precio denominado flete o porte, a conducir de un lugar a otro, por el medio determinado y en el plazo fijado, personas o cosas y entregar estas al destinatario."

El Código de Comercio, ha dejado un amplio margen de configuración y de intervencionismo por parte del Estado, para que este regule la relación y el contrato de transporte; igualmente, para que fije las características de las empresas de servicio público y reglamente su creación y funcionamiento. El artículo 997, modificado por el Decreto 01 de 1990, en su artículo 13, fijó que será

6 Sentencia de Casación Civil de $1^{\circ}$ de Junio de 2005.

7 M.P Jaime Arrubla Paucar. Sentencia -210-2004 el Gobierno quien reglamente el funcionamiento de las empresas de transporte, terminales, centros de información y distribución de transporte, especialmente en cuanto a la seguridad de los pasajeros y la carga, la higiene y la seguridad de los vehículos, naves, aeronaves, puertos, estaciones, bodegas y demás instalaciones, y en cuanto a las tarifas, horarios, itinerarios y reglamentos de las empresas. Así mismo establecerá la escala de sanciones por la violación de normas legales y reglamentarias.

\subsection{Clases de transporte}

Para clasificar el contrato de transporte, se pueden atender a diferentes criterios:

1. Podemos referirnos al modo de transporte como terrestre $^{8}$, aéreo ${ }^{9}$ o marítimo ${ }^{10}$; es de importancia esta clasificación, ya que el tratamiento legal dado en Colombia es diferente para cada uno de estos medios.

2. Mirando a lo que se debe transportar, se clasifica en personas o cosas.

3. Existe el transporte individual, cuando interviene un solo transportador y pluripersonal, cuando intervienen varias personas, ya sea en el traslado de cosas o de personas.

4. También se tiene que el transporte puede ser nacional o internacional, dependiendo del área territorial que comprende.

\subsection{Naturaleza jurídica del contrato de transporte}

El contrato bajo comento tiene una naturaleza jurídica propia y autónoma; significa que es una figura con características individuales, que hace que se distinga de otras instituciones y tipos contractuales; se quiere expresar con ello, que esas características hacen que su relevancia en el ordenamiento no pueda ser sustituida por otro negocio jurídico, sin que con ello deje de

8 Ley 796 de 2002 "Por la cual se expide el código Nacional de Tránsito Terrestre y se dictan otras disposiciones"

9 Ley 105 de 1993 "Por la cual se dictan disposiciones básicas sobre el transporte, se redistribuyen competencias y recursos entre la Nación y las Entidades Territoriales, se reglamenta la planeación en el sector transporte y se dictan otras disposiciones" 10 Decreto 410 de 1971 "Por la cual se expide el código de comercio" 
desatenderse una necesidad que se satisface a través de un servicio público, como lo es el transporte con el cual se logra el cumplimiento de fines, como la movilidad, la libertad de acceso y la libertad de circulación, de todos los habitantes en el territorio nacional.

Por lo anterior, el contrato de transporte se concibe como un contrato sui generis, con una obligación de resultado, consagrada en el Código Civil; el resultado consiste en el traslado incólume de personas o cosas de un lugar a otro. Por esta razón, el riesgo de la actividad pesa sobre el transportista o porteador; el riesgo se materializa cuando no llegan las personas o cosas a su lugar de destino, o cuando llegan tardíamente. ${ }^{11}$

\subsection{Caracteristicas}

La naturaleza jurídica de la cual se ha hecho referencia, se vislumbra a través de las características propias del contrato de transporte, siendo éstas la de ser: consensual, bilateral, oneroso, de tracto sucesivo, nominado y típico ${ }^{12}$; la mencionada clasificación ha sido identificada por la doctrina, cuyo mayor representante es el ex magistrado de la Corte Suprema de Justicia, Jaime Arrubla Paucar; sin embargo, hay teóricos que manejan una clasificación diferente o que tienen algunas divergencias en cuanto a este tema, ya que algunos incorporan características como la de ser un contrato principal y de libre discusión. Así mismo, genera controversia si tal contrato es de ejecución o tracto sucesivo, o si es un contrato con obligaciones de ejecución instantánea.

A continuación se hará una breve referencia y explicación de cada una de estas características:

CONSENSUAL: El contrato de transporte se perfecciona por el simple acuerdo entre las partes; así lo menciona el artículo 981 de la legislación mercantil. Por lo tanto desde el instante en que las partes expresan la voluntad, esto es, el querer de obligarse mutuamente, el negocio jurídico produce todos sus efectos.

En la jurisprudencia de la Corte, se ha reiterado el carácter consensual del contrato, así: "Tratándose de un contrato eminentemente consensual, se perfecciona con el acuerdo de

11 Op. Cit.

12 Ibíd. voluntades de las partes contratantes, pudiendo probarse por cualquiera de los medios legales"13

BILATERAL: Esto quiere decir, que ambas partes se obligan. El transportador a llevar de un lado a otro las cosas o las personas, y el pasajero o remitente a pagar el precio.

ONEROSO: La onerosidad se infiere de la lectura del artículo 981 del decreto 410 de 1971, según el cual una de las partes se obliga a pagar determinado precio o porte por el transporte de cosas o personas, de un lugar determinado a otro. Así mismo, el contrato genera un beneficio mutuo para las partes intervinientes: lucro, o ganancia que se mira como equivalente; por lo cual, de esta característica, también se desprende la conmutatividad del contrato.

DE TRACTO SUCESIVO: Para una parte de la doctrina el contrato de transporte es de ejecución sucesiva, porque es un contrato de duración donde las partes, no pueden despedirse de la obligación en el mismo momento en que esta se perfecciona o, en otras palabras, es de ejecución sucesiva o prestación continuada, por contener una prestación "consistente en varios actos, un conjunto o serie de actos, homogéneos, que no han de ser ejecutados, ni pueden serlo, unitariamente, sino diseminados en el tiempo, y que, por lo mismo, están llamados a prolongarse indefinidamente 0 a proyectarse en un determinado periodo (qui tempus successivum habent)"14

En contraposición a esta tesis, se encuentran quienes consideran la obligación surgida del transporte como un deber jurídico de ejecución instantánea, afirmando que, aun cuando la ejecución de la prestación se puede prolongar en el tiempo, no por eso desaparece su carácter de instantáneo. ${ }^{15}$ "Instantánea, por excelencia, es aquella en que, siendo el objeto unitario o tomándosele como tal, se ha de ejecutar una sola oportunidad y un solo acto. Sirvan los ejemplos

13 M.P José Fernando Ramírez Gómez. Sentencia 033 del 25 de Marzo de 2003.

14 HINESTROSA FORERO. Fernando. Tratado de las obligaciones. Concepto, estructura y vicisitudes. Tomo I. p. 264. Tercera edición. Universidad Externado de Colombia. Bogotá, 2007.

15 BONIVENTO FERNÁNDEZ, José Alejandro. Principales contratos civiles y comerciales. Octava edición. Tomo II. Bogotá: Ediciones el Profesional LTDA., 2009.Pág.191. 
de la entrega (dación, entrega, restitución) de un cuerpo cierto (...), la del flete de un transporte" 16

NOMINADO Y TIPICO: Es nominado, ya que tiene un nombre específico en el sistema legal colombiano; de igual manera, su regulación está establecida por la ley 57 de 1887 y el decreto 410 de 1971.

PRINCIPAL: No requiere de otro contrato o convención para que este surja. Es autónomo por sí mismo y su nacimiento depende de la voluntad de los contratantes. En este punto, vale recordar que, si bien el código civil colombiano, en su artículo 1499, estipula que "El contrato es principal cuando subsiste por sí mismo sin necesidad de otra convención, y accesorio, cuando tiene por objeto asegurar el cumplimiento de una obligación principal, de manera que no pueda subsistir sin ella", como lo indica el maestro OSPINA FERNÁNDEZ "el concepto de accesoriedad debe entenderse, no en función de la clasificación de contratos principales y accesorios a que se refiere el artículo 1499 del código civil, ya que todo contrato es en sí principal, sino en cuanto al contenido de las obligaciones que de un acto jurídico se genera"17.

Una vez que se ha tratado de manera holística las características del contrato de transporte, se examinará más a fondo el transporte de personas, ya que es esta especie dentro del contrato de transporte, la que en verdad nos merece todo la atención. El bicitaxismo, punto medular de este artículo, se enfoca en la mencionada especie contractual, por lo que a continuación se entrará a estudiar y dilucidar el transporte de personas.

\section{EL CONTRATO DE TRANSPORTE TERRESTRE DE PERSONAS}

El contrato de transporte terrestre de personas, es aquel por el cual, una empresa transportadora, asume frente a una persona denominada pasajero, la obligación de trasladarla, de un lugar a otro, previamente determinado, mediante el pago, o la promesa de pago, de un precio en dinero, llamado porte o flete, corriendo

16 HINESTROSA FORERO. Fernando. Op. Cit. p. 264.

17 ABELA MALDONADO, Andrew. Obligaciones con clausula Penal en Derecho de las Obligaciones Tomo I. p. 135. Primera edición. Universidad de los Andes. Bogotá 2009 profesionalmente los riesgos inherentes a tales actos. $^{18}$

\section{ELEMENTOS}

Podemos identificar como elementos o extremos subjetivos del mencionado contrato:

PASAJERO: Persona quien se obliga a pagar un precio y a observar las condiciones de seguridad impuestas por el transportador y por la normativa desarrollada por el Estado, a cambio de que aquel, preste sus servicios, llevándolo a un lugar previamente establecido.

TRANSPORTADOR: Es la empresa que asume frente a una persona indeterminada la obligación de trasladarlo de un lugar a otro, recorrido que debe estar previamente estipulado o pactado; el precio que recibe el transportador, puede ser pagado antes, durante o después de la ejecución del contrato; en todo caso, el transportador, asumirá los riesgos pertinentes.

CAPACIDAD: Se orienta por las normas generales estipuladas por la ley civil, es decir, que son capaces de celebrar este contrato, aquellas personas que la ley haya determinado para tal efecto, siguiendo la regulación sobre las inhabilidades absolutas y relativas expresadas por el artículo 1504 de la ley 57 de 1887.

En este punto hay que aclarar, que si bien este tipo contractual se regula por las normas que para él ha dispuesto el legislador, suele presentarse un fenómeno negocial especial, al validarse el consentimiento tácito. Piénsese en el supuesto de que el transportador deje la puerta abierta de su vehículo, invitando al pasajero a que se suba en él, acontecimiento que efectivamente ocurre con lo cual se perfecciona el contrato, ateniéndonos a la característica de la consensualidad y a los requisitos que debe reunir la oferta y la aceptación en lo que se ha conocido por la doctrina como el itercontractus. "La aceptación tácita es la que se puede deducir de cierta conducta, de cierto comportamiento, que no deja dudad acerca de la voluntad contractual"19

\section{ARRUBLA PAUCAR. Op. cit., $p 89$.}

19 TAMAYO LOMBANA, Alberto. Manual de Obligaciones. El acto o negocio jurídico y otras fuentes de las obligaciones. $P 79$. Séptima edición. Ediciones doctrina y ley. Bogotá, 2008. 
OBJETO DEL CONTRATO: Tiene por objeto un resultado, el cual consiste en trasladar a una persona de un lugar a otro; el transportador, debe hacer todo los posible y lo que este a su alcance para cumplir, de manera óptima e idónea, su obligación de resultado

PRECIO O FLETE: Es la contraprestación a la cual se ve obligado a cumplir el pasajero, por el servicio prestado por parte del transportador; este precio puede ser fijado o estipulado por las partes, en virtud de la autonomía privada de la voluntad de las mismas; no obstante, en muchas ocasiones, quien fija esta tarifa, es el Estado, con su poder de intervencionismo.

\section{BICITAXISMO: UNA CUESTIÓN DE DERECHOS FUNDAMENTALES}

Ya se ha tratado el tema del contrato de transporte, su regulación, su característica y sus elementos; a continuación, se expondrá con más profundidad el tema del bicitaxismo y su relación con el contrato de transporte; también el problema socio-jurídico que de allí se desprende. Para estudiar el tema del bicitaxismo, es pertinente empezar por referirse a leyes expedidas hace ya más de diez años, como la Ley 105 de 1993 y la Ley 336 de 1996, las cuales regulan el tema del transporte, dentro del territorio nacional.

La Ley 336 de 1996 en su acápite de "Sanciones", señala las multas, inmovilizaciones de vehículos, cancelación de licencias, entre otras, siendo de gran importancia el artículo 49, en su literal e), el cual señala que será inmovilizado el equipo que no reúna las condiciones técnicomecánicas requeridas para su operación, o se compruebe que presta un servicio no autorizado. ${ }^{20}$ .$Y$ es en este aparte subrayado, donde surge la duda de si el bicitaxismo es un servicio autorizado o no; porque a su vez, el inciso cuarto del artículo 21 de la misma ley, señala "en todo caso, al usuario se le garantizarán formas alternativas de transporte para su movilización"; entonces, el bicitaxismo, ¿sería una forma alternativa?

Seguramente, para la época de expedición de las leyes antes mencionadas, no se tenía

20 En este último caso, el vehículo será inmovilizado por un término hasta de tres meses $y$, si existiere reincidencia adicionalmente se sancionará con multa de cinco (5) a veinte (20) salarios mínimos mensuales vigentes; claro el concepto de bicitaxismo; éste vino a tomar forma, a partir de una serie de proyectos de acuerdos del Concejo de Bogotá, como por ejemplo, el Acuerdo 396 de 2007; en él se define claramente el concepto de tricimóvil, como: "vehículo para el transporte especializado de pasajeros, constituido bajo el principio de la bicicleta, accionado con tracción humana, con una capacidad de traslado de dos pasajeros adultos sentados y su conductor"21. Así mismo, en la exposición de motivos de dicho acuerdo, se hace referencia al derecho al trabajo y al derecho a escoger profesión u oficio de manera libre, debido a que este medio de transporte genera empleo para personas no profesionales y que carecen de otros medios para su subsistencia. Según datos presentados al Concejo de Bogotá en el año 2004, la construcción de los tricimóviles genera aproximadamente 1.000 empleos directos, de los cuales dependen unas 3.000 personas. Si se tiene en cuenta que existen aproximadamente 1.790 tricimóviles, con igual número de propietarios en la ciudad, y que por cada uno de ellos se crea empleos en la fase de operación, se estará dando trabajo a 2.985 personas, de las cuales dependen aproximadamente 10.500 individuos. ${ }^{22}$

Además de generar empleo para la persona que conduzca este tipo de transporte, se genera trabajo para las personas que queden encargadas del mantenimiento y fabricación del mismo. Además, señala el Doctor Luís Fernando Olivares Rodríguez, este tipo de transporte proporciona una serie de beneficios que se resumen en su no contaminación al medio ambiente, ocupan poco espacio, y no deterioran la malla vial.

Por otro lado, estos vehículos de tracción humana tienen rutas específicas, siendo éstas las calles por donde no hay un servicio de transporte público definido; calles que, por lo general, no cuentan con buses y los taxis que pasan son pocos; el tricimóvil se constituye en el medio adecuado para las personas que no quieren caminar desde donde los dejó el bus, hasta la puerta de sus casas. Otro dato importante que cabe mencionar de este acuerdo, es que para el año 2007, no se había

21 Proyecto de acuerdo no. 396 De 2007: "por el cual se dictan disposiciones relativas a la actividad de los tricimóviles con respecto al tránsito dentro del distrito capital"

22 PROYECTO DE ACUERDO No. 396 DE 2007: "POR EL CUAL SE DICTAN DISPOSICIONES RELATIVAS A LA ACTIVIDAD DE LOS TRICIMÓVILES CON RESPECTO AL TRÁNSITO DENTRO DEL DISTRITO CAPITAL" 
presentado ningún accidente de tránsito donde intervinieran tricimóviles, lo cual demuestra la seguridad de dicho transporte, sumándolo a las demás ventajas antes descritas.

El proyecto de acuerdo distrital que se viene comentando acude a mandatos de la Constitución Política como son el artículo $2^{\circ}$ acerca de los fines esenciales del Estado, los artículos 25 y 26 concernientes al derecho al trabajo y la libertad de escoger profesión u oficio; también acude a la Ley 336 de 1996 para destacar que en su artículo $3^{\text {o }}$ señala que, en la regulación del transporte público, las autoridades competentes deben exigir y verificar las condiciones de seguridad, comodidad y accesibilidad requeridas, que garanticen a los habitantes la eficiente prestación del servicio básico y de los demás niveles que se establezcan al interior de cada modo, dándole prioridad a la utilización de medios de transporte masivo; el artículo $2^{\circ}$ se refiere a que la protección de los usuarios, constituye prioridad esencial en la actividad del sector y del sistema de transporte.

A manera de conclusión preliminar respecto de este acuerdo, considerado el primer esfuerzo del Cabildo de Bogotá para regular la situación del bicitaxismo en la ciudad, se encuentra que contiene los motivos constitucionales y legales esgrimidos para la reglamentación de dicho transporte, las rutas por las que deben transitar, la cantidad máxima de pasajeros que se puedan transportar en él, la tarifa por trayecto, la distancia máxima que puede recorrer y demás reglas para el óptimo funcionamiento de este nuevo medio de transporte.

Ahora bien, ante el fracaso en la votación del proyecto de acuerdo analizado, se presenta el Proyecto de Acuerdo 526 de 2007, en donde se reiteran los motivos expuestos en el proyecto 396 del mismo año, aunque con argumentos de más, que interesa subrayar.

Señala el concejal Isaac Moreno de Caro, ponente del proyecto de acuerdo, que a la luz de la Ley 769 de 2002 "Las bicicletas y triciclos no podrán llevar acompañantes, excepto mediante el uso de dispositivos diseñados especialmente para ello..." (Artículo 95); además, señala el artículo 94 de la misma ley que: "Los conductores y los acompañantes cuando hubieren, deberán utilizar casco de seguridad, de acuerdo como fije el Ministerio de Transporte"23; lo anterior seria, en conclusión, la regulación de utilización de bicicletas y triciclos, como medio de transporte y la posibilidad que éstos lleven pasajeros, siempre y cuando cumplan con medidas de seguridad.

Así las cosas, se proponen otra serie de artículos para regular el transporte de tracción humana (tricimovil o bicitaxi), determinando, al igual que el acuerdo 396, el número de pasajeros que puede llevar, la condición de que el tricimóvil porte una placa, el hecho de que sus pasajeros porten un chaleco reflectivo y un casco, la distancia máxima que pueden recorrer por trayecto y la prohibición de circular por vías principales. El anterior proyecto de acuerdo no fue aprobado por el Concejo de Bogotá, dejando, una vez más, la situación social del bicitaxismo, en el limbo jurídico.

Tres años después, se expide la Ley 1383 del 16 de marzo de 2010, que reforma la Ley 769 de 2002 o Código Nacional de Transito. De esta ley se debe resaltar el artículo 21 por el cual se modifica el artículo 131 de la ley 769, en lo concerniente a las multas imponibles a los infractores de normas de tránsito, conductores de vehículos no automotores, donde caben perfectamente los bicitaxistas, quienes son sujetos de este artículo. La referida norma señala que se impondrá multa a quien preste servicio público con este tipo de vehículos y, además, se inmovilizara el mismo.

\subsection{Sentencia C-981 de 2010: la Corte Constitucional garante de los derechos fundamentales}

A pesar del contenido de este artículo, la Corte Constitucional no demoró en pronunciarse por medio de la sentencia C-981 de 2010, donde se demandó la inconstitucionalidad del literal A-12 del artículo 131 de la ley 769 de 2002, tal y como fue adicionado por el artículo 21 de la Ley 1383 de 2010, antes comentado.

En esta providencia, a juicio del demandante, la disposición referida vulneraba el preámbulo y los artículos 13, 25, 53, 58, 333 de la Constitución Política, así como el principio de confianza legítima. La norma acusada, al prohibir la

23 Proyecto de acuerdo no. 526 De 2007 "por el cual se autoriza provisionalmente la circulación de tricimóviles en la ciudad como medio de transporte alternativo" 
prestación del servicio público de transporte en vehículos no automotores o de tracción animal, según el demandante, desconocía el derecho al trabajo, pues, las personas que manejan este tipo de vehículos, por su estado de vulnerabilidad, no saben realizar ninguna otra actividad. ${ }^{24}$

Entre otros argumentos, el accionante menciona que el artículo 98 de la Ley 769 de 2002, en el aparte que disponía la erradicación de los vehículos de tracción animal en el término de un año, fue declarado inexequible mediante Sentencia C-355 de 2003, con la consideración de que violaba los derechos al trabajo en conexidad con el mínimo vital y a la igualdad y desconocía el principio de la confianza legítima. Sin embargo, con la ley 1383 de 2010, se presentan condiciones más gravosas para las personas que trabajan con estos vehículos, toda vez que la norma está encaminada a suspender, del todo, este tipo de servicio.

Desde el punto de vista del demandante, la norma acusada vulneraba la dignidad humana y la libertad de las personas que han escogido este medio como su trabajo, para así conseguir un sustento para sobrevivir; con la norma demandada se les estaría coartando este derecho y la posibilidad de escoger profesión u oficio, así como la libertad de desplazarse libremente.

Por último, argumenta el actor, que la ley vulnera el principio de confianza legítima, el cual ha sido definido por la Corte como una proyección de la buena fe que debe gobernar la relación entre las autoridades y los particulares, puesto que la disposición demandada no tuvo en cuenta el impacto que la prohibición en ella contenida, generaría en muchos colombianos, sin que se proponga ninguna alternativa para quienes viven de esa actividad. ${ }^{25}$

Para resolver la constitucionalidad de la norma demandada en esta sentencia, la Corte se plantea el siguiente problema jurídico: El numeral 12 del literal A del artículo 131 de la Ley 769 de 2002, adicionado por el artículo 21 de la Ley 1383 de 2010, al consagrar como infracción de tránsito el hecho de prestar servicio público

24 CORTE CONSTITUCIONAL, Sentencia c 981 del $1^{\circ}$ de diciembre de 2010, M.P Gabriel Eduardo Mendoza Martelo, pag. 6.

25 CORTE CONSTITUCIONAL, Sentencia c 981 del $1^{\circ}$ de diciembre de 2010, M.P Gabriel Eduardo Mendoza Martelo, pag. 7 con vehículo no automotor o de tracción animal, ¿resulta violatorio del principio de igualdad (C.P. art. 13); del derecho al trabajo (C.P. Arts. 25 y 53); del derecho de propiedad (C.P. art. 58); de la libertad de empresa (C.P. art 355) y del principio de confianza legítima?

Después de ahondar en los antecedentes de la norma, la Corte menciona las diferentes leyes que han regulado el tema del transporte público y privado, para después sintetizar tal situación con un concepto de mayo de 2006 de la Sala de Consulta y Servicio Civil del Consejo de Estado, sobre las características que se predican del servicio público de transporte:

- Su objeto consiste en movilizar personas o cosas de un lugar a otro, a cambio a una contraprestación pactada normalmente en dinero.

- Cumple la función de satisfacer las necesidades de transporte de la comunidad, mediante el ofrecimiento público en el contexto de la libre competencia.

- El carácter de servicio público esencial implica la prevalencia del interés público sobre el interés particular, especialmente en relación con la garantía de su prestación - la cual debe ser óptima, eficiente, continua e ininterrumpida -, y la seguridad de los usuarios - que constituye prioridad esencial en la actividad del sector y del sistema de transporte (Ley 336/96, art. $2^{\circ}$ ).

- El servicio público se presta a través de empresas organizadas para ese fin y habilitadas por el Estado.

- Su prestación sólo puede hacerse con equipos matriculados o registrados para dicho servicio.

- Implica necesariamente la celebración de un contrato de transporte entre la empresa y el usuario. $^{26}$

Después de la anterior aclaración, la Corte se percata de que la ley, al regular los modos de operación del transporte público, se ocupó del transporte terrestre automotor, el transporte marítimo, el transporte fluvial y el transporte

26 Consejo de Estado, Sala de Consulta y Servicio Civil, Concepto de 18 de mayo de 2006, Radicación número: 11001-03-06-0002006-00040-00(1740). 
aéreo; por ende, no quedaron comprendidas en la regulación legal otras modalidades de transporte, como el no automotor o el de tracción animal; pero aclara, que el hecho de que este tipo de transporte no se encuentre regulado, no quiere decir que no exista en la realidad, sino que se desarrolla de manera informal o ha sido objeto de regulación en el nivel territorial en el que opera, como por ejemplo, en Bogotá; en esta ciudad se promulgó el Decreto 257 de 1997, que contiene normas que aluden al transporte de escombros en vehículos de tracción animal, y el Decreto 510 de 2003 que reglamenta el tránsito de los vehículos de tracción animal en el Distrito Capital, en los términos de la Sentencia de C-355 de 2003.

En el alcance específico de la norma demandada, la Corte encuentra que se desprenden unas características para la infracción prevista en la disposición:

- Se aplica en todo el territorio nacional, sin distinguir entre categorías de municipios, zonas rurales o urbanas o tipos de vía.

- Se aplica para todo vehículo no automotor o de tracción animal, que exista o que pueda llegar a existir.

- Se predica de toda actividad de transporte público, sin distinguir entre si es permanente $u$ ocasional y sin establecer distinciones en relación con los horarios del servicio.

- Implica una prohibición absoluta para la prestación de servicio público, esto es para transportar a personas o a cosas a cambio de una remuneración. ${ }^{27}$

Para contextualizar lo anterior, la Corte señala que el transporte público es considerado un servicio público esencial y, por ende, el legislador tiene el deber de regularlo, como se lo ordena la Constitución Política. Por otra parte, señala la Corte, constituye una actividad llena de riesgos para las personas y las cosas, por lo cual se debe regular estrictamente la actividad del tráfico automotor. Es el carácter riesgoso que representa el transporte público, el que exige del legislador una reglamentación con reglas y prohibiciones en aras de la seguridad de las personas y de los

27 CORTE CONSTITUCIONAL, Sentencia c 981 del $1^{\circ}$ de diciembre de 2010, M.P Gabriel Eduardo Mendoza Martelo, pag. 22 bienes. Sin embargo, la potestad del legislador no es absoluta, ni puede ejercerse de manera arbitraria, sino que las restricciones que se impongan deben ser razonables y proporcionadas, en función de fines constitucionalmente legítimos.

En esta sentencia la Corte encuentra una tensión, entre la amplia potestad que tiene el Estado para regular el servicio público de transporte y la exigencia de que las restricciones que se impongan a las personas tengan claro sustento, en función de fines constitucionalmente admisibles, y sean razonables y proporcionadas. Por esta razón la Corte encuentra necesario acudir a un test de proporcionalidad, para verificar si la restricción impuesta en la norma es razonable y proporcionada, y por consiguiente ajustada a la Constitución o, si por el contrario, se aparta de esos principios y es violatoria del ordenamiento superior.

Con respecto al tema del test de proporcionalidad, el cual ha sido aplicado por la Corte Constitucional en varias ocasiones, se ha precisado que cuando diversos principios constitucionales entran en colisión, corresponde al juez constitucional, estudiar la constitucionalidad de la finalidad perseguida por la medida examinada y, además, examinar si la reducción del derecho es proporcionada, a la luz de la importancia del principio afectado. Para ello, debe el juez: primero, determinar si el trato diferente y la restricción a los derechos constitucionales son 'adecuados' para lograr el fin perseguido; segundo, si son 'necesarios', en el sentido de que no exista otro medio menos oneroso en términos de sacrificio de otros principios constitucionales para alcanzar el fin perseguido y, tercero, si son 'proporcionados stricto sensu', esto es, que no se sacrifiquen valores y principios que tengan un mayor peso que el principio que se pretende satisfacer." 28

En lo que respecta a la norma demandada, encuentra la Corte que tiene una finalidad legitima a la luz de la Constitución; si bien es cierto, no se conocen los motivos del legislador para haber planteado tal prohibición, o sanción, a las personas que presten el servicio público por medio de transporte no automotor o de tracción animal, se puede concluir que el legislador lo hizo en pro de la seguridad, la movilidad y la

28 CORTE CONSTITUCIONAL, Sentencia C-309 de 1997. 
salubridad, por lo cual está acorde con la Carta Política. Por otro lado, es claro para este Tribunal que la norma demandada, como prohibición que es, coarta y restringe el derecho al libre desarrollo de la personalidad, al trabajo, a la libertad de escoger profesión u oficio de quienes venían desempeñando la actividad sancionada por la norma; entonces, la Corte deberá examinar si esta restricción es proporcionada por encontrarse en contraposición con los valores y principios ya mencionados.

Está claro que la restricción contenida en la norma demandada es adecuada para el fin propuesto; pues al imponer una sanción a quienes presten servicio público en transporte no automotor o de tracción animal, se previene de forma absoluta el riesgo y los inconvenientes que genera dicha actividad. Sin embargo, la Corte debe pasar a establecer si dicha medida resulta necesaria, determinando si no existen, o si se han evaluado, alternativas distintas, que resulten menos onerosas en términos de los principios y derechos restringidos. Es en este segundo paso del test de proporcionalidad, donde el Tribunal Constitucional encuentra que la norma demandada no supera el examen; lo anterior, porque para atender las finalidades legitimas de seguridad, movilidad, salubridad o preservación del espacio público, basta acudir a la reglamentación del transporte público en vehículos no automotores o de tracción animal, estableciendo restricciones para la prestación del mismo, en razón al tipo de vehículo o a la naturaleza de las vías, sin que sea necesaria una prohibición absoluta de esta actividad. ${ }^{29}$ Para la Corte, es posible que existan reglas o restricciones sobre temas específicos de los vehículos arriba comentados, pero no una exclusión total, como lo hace la norma demandada.

Sumado a lo anterior, la norma examinada vulnera el derecho al trabajo con la prohibición absoluta que hace acerca de la prestación de servicio público por los vehículos no automotores o de tracción animal, porque estaría coartando a los dueños de estos vehículos para explotarlos económicamente $\mathrm{y}$, así mismo, impediría la obtención de un sustento para su supervivencia.

29 CORTE CONSTITUCIONAL, Sentencia c 981 del $1^{\circ}$ de diciembre de 2010, M.P Gabriel Eduardo Mendoza Martelo, pag.26
Finalmente, para su decisión, la Corte Constitucional se adhiere y se pronuncia en los términos de la sentencia C-355 de 2003 señalando que en aras de preservar la decisión adoptada por el legislador dentro de su ámbito de configuración, declarará la exequibilidad del numeral 12 del literal A del artículo 131 de la Ley 769 de 2002, adicionado por el artículo 21 de la Ley 1383 de 2010, bajo el entendido de que la sanción allí prevista sólo será aplicable, previa reglamentación por las autoridades territoriales competentes, en la que se señalen las condiciones de tiempo, de modo y de lugar en las que se aplicaría la restricción allí consagrada. ${ }^{30}$

\subsection{Acuerdo 260 de 2012: una nueva oportunidad para el bicitaxismo}

En el año 2012, por medio del proyecto de acuerdo número 260, el Consejo de Bogotá, tomó como fundamento la sentencia C-981 de 2010, antes tratada, para exponer los motivos por los cuales se debe reglamentar la prestación del servicio de transporte público terrestre no automotor individual de pasajeros en el Distrito Capital. Se empieza por detectar que el fenómeno de los bicitaxis data de hace 20 años; sin embargo fue en 2004 cuando esta clase de vehículos comenzaron a circular por unos sectores determinados de las localidades de Bogotá, como Suba, Kennedy y Bosa.

Este medio de transporte está destinado a sectores donde el servicio colectivo no llega, o llega de manera precaria, utilizándose el tricimovil para suplir la necesidad de transportarse, en trayectos que pueden ir de las 5 a las 20 cuadras. Este fenómeno puede observarse, en mayor medida, en estaciones "intermedias" de Transmilenio, debido a que el trayecto desde la estación hasta el destino de la persona, es demasiado extenso, más cuando por allí no pasa el servicio colectivo; entonces la persona debe decidir, entre caminar ese largo camino, pagar una carrera mínima de un taxi, o pagar la tercera parte de esa carrera mínima, tomando un bicitaxi.

Más adelante se hace una exposición de datos estadísticos acerca del valor de un trayecto en bicitaxi, cuánto ganan en promedio los conductores de estos vehículos y cómo funciona

30 CORTE CONSTITUCIONAL, Sentencia c 981 del $1^{\circ}$ de diciembre de 2010, M.P Gabriel Eduardo Mendoza Martelo, pag.29 
esta organización, dependiendo el sector en que se encuentren los bicitaxistas, para determinar que, con más de 5.000 conductores, cerca de 150.000 usuarios diarios y presencia en al menos 11 localidades, el bicitaxismo es una realidad que las autoridades nacionales y distritales ya no pueden ignorar. Sin embargo, así como los bicitaxis prestan un servicio conveniente, ecológico y económico a los usuarios, las condiciones de éste no son óptimas y, frecuentemente, se encuentran los siguientes inconvenientes:

- Vehículos sin las condiciones de seguridad adecuadas, debido a un diseño y una construcción deficientes.

- Vehículos circulando por vías arterias donde ponen en peligro la integridad física del conductor y de los pasajeros.

- Menores de edad conduciendo los vehículos.

- Conductores que maltratan o cobran más de lo "justo", a los pasajeros.

- Vehículos estacionados en el espacio público, donde obstaculizan el tránsito de peatones.

- Conflictos entre conductores o empresas de bicitaxis, sobre quién tiene el derecho a operar cierta ruta.

- Conductores sin ningún tipo de seguridad social o protección, contra riesgos profesionales.

- Ninguna contribución de conductores o propietarios de bicitaxi al Distrito y al mantenimiento de la infraestructura que utilizan. ${ }^{31}$

Muchos de estos problemas serían solucionados con una reglamentación acerca de la prestación de servicio público por parte de vehículos no automotores; no obstante, la posición del Ministerio de Transporte, ha sido tratar de evitar este hecho imponiendo sanciones, multas e inmovilizaciones a los vehículos de esta naturaleza, que presten el servicio público.

Con el fin de reglamentar la situación del transporte no automotor se han dado varios proyectos de acuerdo, sin resultado alguno, señalando como finalidad la necesidad de dignificarlo y volverlo más seguro para conductores y usuarios; lo que propone este proyecto de acuerdo, en concreto, es tomar como base la sentencia C-981 de 2010, la cual

31 Proyecto de acuerdo $n^{\circ} 260$ de 2012 "por medio del cual se ordena la reglamentación de la prestación del servicio de transporte público terrestre no automotor individual de pasajeros en el distrito" no había sido tenida en cuenta para los otros proyectos; sin embargo, la Secretaría Distrital de Movilidad no ha reglamentado la prestación del servicio de transporte público en vehículos no motorizados en Bogotá, argumentando que es necesario que el Gobierno Nacional, a través del Ministerio de Transporte, homologue y matricule los vehículos, y fije los criterios para la habilitación de las empresas operadoras por parte de las entidades territoriales, para así ponerle orden a un fenómeno que, siendo eminentemente positivo para la ciudad, necesita la intervención constructiva del Estado y de las entidades del distrito de manera urgente. ${ }^{32}$

Con una reglamentación pronta y completa que fije las condiciones en las que debe operar el vehículo, los requisitos que deben cumplir las empresas y los conductores, las especificaciones de las rutas, entre otras, traería a los conductores y a los usuarios, importantes beneficios, como: un servicio seguro y económico que permita a los usuarios hacer desplazamientos cortos complementarios a los del transporte colectivo o masivo; un vehículo cómodo y seguro, en el cual es menos probable que se tengan accidentes; tranquilidad al saber con certeza que el conductor está capacitado para conducir su vehículo y la posibilidad de tener una tarifa definida. Para los conductores permitiría la tranquilidad de no ser sancionados por la Policía, si cumplen con la regulación definida por la Secretaría de Movilidad; acceso a seguridad social y a un seguro de accidentes contra terceros; claridad en precios para ingresar a operar un vehículo en cierta ruta; mejores condiciones de los vehículos en los que trabajan en cuanto a seguridad y comodidad, entre otros.

Se puede concluir que antes de la sentencia C-981 de 2010, existía un vacío legal que permitía a las autoridades de tránsito dar por prohibida la prestación del servicio público de transporte no automotor o de tracción animal; con dicha providencia es imperativo que cada entidad territorial regule la prestación de dicho servicio, pues hasta que ello no se realice, es ilegal seguir sancionando a las personas que actualmente prestan este servicio.
32 Proyecto de acuerdo $n^{\circ} 260$ de 2012 "por medio del cual se ordena la reglamentación de la prestación del servicio de transporte público terrestre no automotor individual de pasajeros en el distrito" 
En suma, la prestación del servicio público de transporte en vehículos no automotores es una realidad tal y como fue reconocida por el Tribunal, así legalmente no esté regulada; por ende, no puede ser absolutamente restringida, sino que debe reglamentarse por la autoridad competente, que para el caso de Bogotá, es el Concejo y el Alcalde Mayor.

Después de esta exposición de motivos, el proyecto de acuerdo contiene dos artículos, uno de los cuales ordena a la Administración Distrital reglamentar, en el término de 12 meses, la prestación del servicio de transporte público terrestre no automotor individual de pasajeros en Bogotá. No obstante lo anterior, este proyecto tampoco caló en el Concejo de Bogotá, por lo que la situación socio-jurídica, sigue sin regulación; la orden emanada de la Corte Constitucional se ha desatendido, generando, a su vez, vulneración de la Carta Política, por cuenta de las autoridades distritales.

\subsection{Responsabilidad civil del transportador, como garantia de protección de los derechos del pasajero}

En el acápite anterior se hizo un recuento de los diferentes intentos por parte de algunos concejales del cabildo de la ciudad de Bogotá por regular la actividad transportadora del bicitaxismo, a través de los diversos proyectos de acuerdo, previendo la tutela de una variada lista de derechos fundamentales de los conductores y propietarios de estos medios de transporte. El bicitaxismo requiere la intervención del legislador para que le dé una orientación pronta a esta relación contractual, ya sea a través de una ley de la república en el orden nacional, o de un acuerdo distrital o municipal, en el orden territorial; por cuanto también se ven menoscabados los derechos de los pasajeros, al no tener claridad acerca de la validez del contrato celebrado y, por ende, el régimen jurídico de responsabilidad que se derivaría en el caso que, como consecuencia de la utilización de este servicio, se causen daños a la vida, a los bienes o a la integridad de las personas que hagan uso de él.

A continuación se procederá a analizar los elementos de la responsabilidad civil, para después, a través del método deductivo, identificar cuál régimen jurídico de responsabilidad es aplicable a los casos ya mencionados.
En este orden de ideas, la responsabilidad civil es entendida como fuente de obligaciones, debido a que somete a quien ha causado un daño, a repararlo. Es concebida, de igual manera, como una deuda de reparación que pesa sobre el autor del perjuicio, en provecho de la víctima, tal como enuncia Henri, León Mazeaud ${ }^{33}$

\subsubsection{Estructura de la responsabilidad civil}

Entendido el concepto central, al analizar el caso del contrato de transporte en el que el pasajero puede llegar a sufrir una serie de daños, a causa del incumplimiento de la obligación accesoria de seguridad, a cargo del transportador, se tiene que determinar si se configura la estructura de la responsabilidad civil. Esta última, impone la presencia de tres elementos:

I) La acción u omisión culposa o dolosa del dañador. La culpa en la responsabilidad contractual dependerá de la clase de contrato que se haya incumplido.

En el caso del contrato de transporte, nos encontramos frente a un contrato que genera obligaciones de resultado; por lo que las partes, o por lo menos una de ellas, deben cumplir una prestación específica o concreta, a la que se obligó con razón del contrato.

Dentro del proceso de estos contratos, quien tiene la obligación de resultado, queda cobijado por una presunción de derecho sobre la culpa. De entrada, el sujeto se presume legalmente responsable. En el proceso no se va a discutir la culpa, no deberá demostrarse ni por la víctima ni por el dañador. La defensa apunta a desvanecer el nexo causal.

Dentro de la responsabilidad del transportista, la jurisprudencia ha aclarado que:

(...) del empresario del transporte ha de esperarse la adopción de todas las medidas que, según las exigencias de la profesión, sean requeridas para evitar la realización del daño o su agravación, con lo que el rigor con el que se debe examinar su actuación sube de punto, pues de él no se espera, simplemente, lo que una persona común habría hecho, sino que la colectividad confía en que el transportador se comporte como lo haría alguien con la preparación, habilitación y experiencia

33 MAZEAUD, Henri y Leon, Tratado de Responsabilidad Civil Tomo I, Editorial Comlex, Mexico D.F, 1945. 
suficientes para enfrentar y superar los distintos riesgos que cotidianamente se presentan en su actividad." ${ }^{4}$

II) El daño en la victima: Arturo Alessandri Rodríguez $^{35}$ lo define como el detrimento, menoscabo, dolor o molestia que sufre un individuo en su persona, bienes, libertad, honor, crédito, afectos, creencias etc. Para que se configure, se deben cumplir tres requisitos esenciales: (a) que sea subsistente, es decir que sea actual, que no se haya cancelado indemnización alguna; (b) que sea personal, que la persona sea víctima directa del hecho dañoso; (c) que sea cierta, que el perjuicio se haya configurado.

III) El nexo causal. Es complejo definir qué es el nexo causal, ya que entrelaza una compleja discusión tanto en el terreno práctico como teórico; sin embargo, existen diferentes teorías acerca del tema a tratar; por ello, se hará un esbozo de lo que es el nexo causal.

Para empezar, hay que decir que existe una causalidad fáctica y otra jurídica; pero, puede pasar, que en el campo ya sea práctico o teórico, no se constituya causalidad fáctica pero si haya causalidad jurídica; lo que se quiere dar a entender es que el hecho generador de la causalidad, es imputable jurídicamente al dañador, lo que configuraría la causalidad jurídica; sin embargo, hay que tener en cuenta que si el daño que le es imputable al dañador se ve estructurado por una causa extraña, en ese instante no se configuraría el nexo causal existente sino que, por el contrario, este se rompería y, por ende, no se configuraría el "trípode" necesario en la estructuración de una responsabilidad civil.

De igual forma existe una causalidad jurídica o moral $^{36}$; se presentan casos, en los cuales, un agente omite una conducta a la cual se ve obligado, ya sea legal o contractualmente y, por esa omisión, se presentan una serie de fenómenos que, como final, dan lugar a la producción de un daño.

34 Corte Suprema de Justicia. Sala de Casación Civil. M.P. Arturo Solarte Rodríguez. Sentencia del 16 de diciembre de 2010. Referencia 05001-3103-010-2000-00012-01.

35 Rodriguez, arturo alessandri de la responsabilidad extracontractual en el derecho civil tomo $i$, santiago de chile 1987. Editorial universal.

36 Tamayo Jaramillo, Javier, tratado de responsabilidad civil tomo i, bogotá, 5ae ed. Editorial legis, 2010
En igual sentido, puede que no sólo ocurra un daño, sino que exista una pluralidad de daños; por esto, quien ha sido víctima de este daño, tendrá que probar diferentes nexos de causalidad, no sólo aquel por el cual ha sido víctima de un daño. Es así como el profesor Tamayo Jaramillo trae a colación una actividad peligrosa, como es el transporte de pasajeros. Para el caso concreto del bicitaxismo, la persona afectada por el daño, tiene que probar que esa conducta le produjo un daño; también tiene que establecer que la persona a la cual se le va a imputar jurídicamente ese daño, tenía alguna injerencia en la actividad peligrosa. Se tiene que demostrar, en efecto, que la persona a la cual se va a demandar, tenía bajo su dirección y control esa actividad, o que la persona que estaba bajo su cuidado, fue quien cometió ese daño; momento en el cual se tendría que probar el nexo causal que había entre este y su guardián.

Sin embargo, la ley trae algunas excepciones al deber de probar el nexo causal, ya que en algunas actividades este se presume y por ende se exonera a la víctima de probar este nexo de causalidad.

De esta manera se tiene que en aquellos contratos en los cuales se exige del deudor una obligación de seguridad, ya sea frente una persona o una cosa, la ley presume que todos los daños que le sucedan a la persona o a la cosa que está bajo su cuidado, han sido causados por este. ${ }^{37}$

Tenemos así que en el transporte de cosas o de personas, la víctima no tiene por qué probar que el dañador efectivamente es el responsable de ello, sino que se presume por la actividad peligrosa que está ejecutando, solo basta que establecer que el daño se realizó en la actividad transportadora.

\subsubsection{Elementos estructurales de la responsabilidad civil contractual:}

En el caso del bicitaxismo, se debe establecer si se configuran los elementos estructurales necesarios para hablar de una responsabilidad contractual; desde este punto de vista es necesario:

I) Existencia de un vínculo jurídico negocial, entre la víctima y el dañador:

Para poder establecer si el contrato existe, se deben observar si los elementos esenciales del

37 Ibid. 
mismo se dan o no. De acuerdo al artículo 1501 del Código Civil: "Son de la esencia de un contrato aquellas cosas sin las cuales, o no produce efecto alguno, o degeneran en otro contrato diferente". Por lo tanto los elementos esenciales del contrato son aquellos sin los cuales el negocio no existe.

En el caso particular, se manifiesta la existencia de un contrato de transporte, cuyo carácter es consensual y, como tal, se perfecciona con el simple acuerdo de las partes; además, de probarse respecto a las formas legales, estipuladas en el artículo 981 del Código de Comercio, siendo este acuerdo, el traslado de la persona y el precio del mismo, a través del medio de transporte terrestre. Además es definido, en el mismo artículo, como un contrato por medio del cual una de las partes se obliga para con la otra, a cambio de un precio, a conducir de un lugar a otro, por determinado medio y en el plazo fijado, personas o cosas y entregar éstas al destinatario.

Para la doctrina, en el contrato de transporte "Además de los requisitos comunes para todo acto o negocio jurídico, capacidad, consentimiento, objeto licito y causa licita, se requiere del precio." ${ }^{38}$, por tratarse de un contrato eminentemente oneroso, donde "ambas partes se gravan y benefician recíprocamente. El transportador se afecta con los actos del transporte, pero se beneficia con el precio, y el pasajero asume la obligación de pagar el pasaje y se beneficia del acto del transporte"39.

En el pago del pasaje, los usuarios lo hacen al conductor directamente; esto no le quita la esencia al contrato, ya que el conductor es quien contrata de manera directa, dada la naturaleza de su oficio y, más aun, teniendo en cuenta que en muchos de los casos no se encuentra afiliado a empresa alguna; por lo tanto, encontramos que estipuladas las condiciones del transporte en horario normal y aprobado por parte del usuario el medio de transporte a usar, se debe entender que se da por constituido el contrato.

Lo anterior nos permite afirmar que el contrato de transporte bajo estas condiciones existe,

38 BONIVENTO FERNÁNDEZ, José Alejandro. Principales contratos civiles y comerciales. Octava edición. Tomo II. Bogotá: Ediciones el Profesional LTDA., 2009.Pág.192.

39 Ibid.P191 por lo que el primer elemento estructural de la responsabilidad civil contractual, se configura.

\section{II) Que este vínculo jurídico sea válido:}

Como ya se dijo, en el caso concreto, el contrato de transporte existe, pues se dan sus elementos esenciales. Al existir este vínculo jurídico negocial, surge a la vida jurídica con una presunción legal de validez, y al no poderse evidenciar a simple vista factores de nulidad, se puede entender el negocio como válido, cumpliendo de este modo con el segundo elemento de la responsabilidad civil contractual.

III) Que haya un incumplimiento de las obligaciones, que nacen del vínculo jurídico.

Ahora bien, en el punto del incumplimiento, cuestión esta necesaria para hablar de la responsabilidad por parte del posible dañador, este se configuraría en caso de no cumplirse la obligación principal por parte del conductor, estipulada en el artículo 982 del Código de Comercio, el cual indica que se debe conducir a las personas sanas y salvas al lugar de destino, también el código civil lo establece en los artículos 2072 y 2073, en donde el transportador tiene una obligación de seguridad y de resultado $y$, en consecuencia, responde por cualquier daño que puedan sufrir los pasajeros durante la ejecución. En este caso, basta el hecho objetivo del accidente sufrido por la víctima para que haya responsabilidad por parte del transportador, sin que este pueda alegar ninguna causal de exoneración. De acuerdo con ello, el artículo 992 del código de comercio establece que el transportador solo se exonera de esa responsabilidad probando una causa extraña, cual puede ser la fuerza mayor, el hecho exclusivo de terceros y la culpa de la víctima.

Es así como la Honorable Corte Suprema de Justicia, en consideración del artículo 1003 del código de comercio que consagra la responsabilidad del transportador, afirma:

Con motivo de ser el transporte una clásica actividad peligrosa, que de suyo implica un riesgo para la sociedad, máxime cuando la conducción es de personas, la inejecución o ejecución defectuosa del contrato de transporte considera o presume la ley que obedece a culpa de quien lo explota... ${ }^{40}$

40 Corte Suprema de Justicia, Sala de Casación Civil, Sentencia: diecinueve (19) de abril de 1979, pagina 90. 
En cuanto a las obligaciones del transportador para apoyar, aún más, las aseveraciones hechas anteriormente, la jurisprudencia y la doctrina han decantado sobre la obligación del transportador:

(...) la del transportador es una obligación de resultado, en la medida en que para cumplirla no le basta simplemente con poner toda su diligencia y cuidado en la conducción de las personas o las cosas, pues con arreglo a dicha preceptiva menester es que la realice en perfectas condiciones, de forma tal que solamente podría eximirse de ello demostrando la concurrencia de alguno de los acontecimientos que dependen de lo que se ha denominado una 'causa extraña', vale decir, aquellos en que, como sucede con el caso fortuito o la fuerza mayor, entre el hecho y el daño se ha roto el nexo causal, indispensable para la configuración de la responsabilidad, lo cual implica naturalmente que se adoptaron 'todas las medidas razonables' de un acarreador profesional para evitar el daño o su agravación ${ }^{41}$

VI) Que ese incumplimiento haya causado un perjuicio

Este incumplimiento del contrato, por consiguiente, debe generar un perjuicio entendido como "la disminución patrimonial que sufre una persona como consecuencia del daño"42, que a su vez, se puede entender como la simple destrucción o deterioro de un objeto. Esta distinción es importante, pues como lo hacen notar algunos doctrinantes, la simple destrucción de una cosa no constituye un perjuicio a la luz de la responsabilidad civil. Solo en la medida en que esa destrucción o deterioro tenga repercusión en los derechos o facultades patrimoniales de una persona, cabe hablar de perjuicio indemnizable.

Es importante recordar que el perjuicio debe cumplir con unas condiciones esenciales para que este obtenga su carácter de indemnizable. Estas características han sido identificadas, tanto por la doctrina como por la jurisprudencia, otorgándoles una especial relevancia, éstas son que el perjuicio debe ser cierto, directo y actual. "En cuanto a las condiciones del perjuicio indemnizable, decimos que este debe ser cierto; y la persona que reclama la indemnización deber ser la misma que resulto

41 Corte Suprema de Justicia, Sala de Casación Civil, Sentencia Primero de Junio de 2005 Exp. No 1999-00666-01.

42 HENAO PÉREZ, Juan Carlos. El Daño. Bogotá: Universidad Externado,1998,pág.77 perjudicada, aunque el primer bien lesionado no fuera de su propiedad o no fuera su propia integridad la que se vio lesionada..." ${ }^{43}$.

En la categorización de los perjuicios, numerosos doctrinantes coinciden en que estos se pueden dividir:

a. Patrimonial: Que a su vez se subdivide en daño emergente y lucro cesante; el primero, entendido como las erogaciones que tiene que pagar con ocasión del daño y, el segundo, consistente en lo que la víctima dejo de percibir con ocasión del daño.

b. Extrapatrimonial: entendido como un menoscabo de la emocionalidad, la psiquis, la vida misma de la víctima. Este se clasifica en daño moral, daño a la vida de relación, daño al proyecto de vida y daño biológico o corporal.

\section{V) Que el perjuicio no haya sido resarcido}

Requisito indispensable para estructurar la responsabilidad civil contractual, por lo cual se puede afirmar que esta es la vía idónea para ejercer la acción, en caso de un incumplimiento por parte de un operador de bicitaxi.

\section{CONCLUSIÓN}

Diversas son las posiciones que se han advertido a lo largo de este artículo, respecto de la necesidad o no, de regular la actividad del bicitaxismo en Bogotá. Para un sector de la sociedad, liderado por la secretaria de movilidad de la ciudad, tal actividad no debe ser legislada, por cuanto el tricimóvil no presenta las condiciones de seguridad necesarias para el pasajero; además, que observa cierta inutilidad de este servicio, pues asevera que el Sistema Integrado de Transporte Público, junto con el sistema de transporte masivo Transmilenio, son suficientes para atender las necesidades de los ciudadanos; sin embargo, para otro sector mayoritario, representado por la célula política de la ciudad, que en diversas ocasiones ha intentado regular la materia, sin contar con los votos suficientes para su aprobación, las ventajas que representaría la reglamentación de este medio de transporte estarían dadas por mayores garantías para los conductores, representadas en el acceso al sistema de seguridad social, además

43 TAMAYO JARAMILLO, Javier. Tratado de responsabilidad civil. Tomo II. Quinta reimpresión. Bogotá: Legis 2010. P.335 
de contar con un contrato de trabajo que exigiría, al propietario del vehículo, el deber de cancelar un salario que le asegure una vida digna al trabajador. Además, permitiría un aumento del erario, a través de tributos que tendría esta actividad, por el uso de la malla vial, así como una alternativa de solución al problema de movilidad de la ciudad.

La Corte Constitucional, en ejercicio de su misión pendular dentro del Estado Social de Derecho, en la guarda de la integridad y supremacía de la Constitución, ha entendido que, incluso, las relaciones contractuales están irradiadas por el poder del texto superior por lo que, no solo es función de las autoridades proteger los derechos fundamentales, sino también la actuación de los particulares, limitando, incluso, caros principios del derecho privado, como la autonomía de la voluntad. La Corte ha interpretado que, en el caso de la regulación del transporte a través de vehículos no motorizados, la potestad de configuración legislativa no es absoluta, estando limitada por los derecho fundamentales de todos los habitantes en el territorio colombiano, reconocidos no solo por la Constitución Política de 1991, sino por tratados internacionales como la Convención Americana de Derechos Humanos que reconocen la libertad de las personas de escoger profesión u oficio, así como el derecho al trabajo, derechos estos que son garantizados si se regula la actividad del bicitaxismo. Así, no sólo se protegerían los derechos cardinales de los operados y propietarios de estos vehículos, sino también se tendería a proteger el orden público y el bienestar colectivo, a través del intervencionismo del Estado. Además se aseguraría un mecanismo idóneo para que los usuarios de estos medios no convencionales de transporte, puedan pedir la reparación de los perjuicios causados por la utilización de los bicitaxis, reconociéndose la cláusula vital del Estado Social de Derecho, que busca asegurar la igualdad de todos frente a la ley. 


\section{BIBLIOGRAFÍA}

\section{DOCTRINALES}

- ABELA MALDONADO, Andrew. "Obligaciones con cláusula Penal en Derecho de las Obligaciones". Tomo I. Primera Edición. Universidad de los Andes. Bogotá, 2009.

- BONIVENTO FERNÁNDEZ, José Alejandro. "Principales contratos civiles y comerciales". Octava edición. Tomo II. Bogotá: Ediciones el Profesional LTDA., 2009.

- FERRAJOLI, Luigi. "Democracia y garantismo". Edición de Miguel Carbonell. Editorial Trotta S.A. Madrid. 2008.

- HENAO PÉREZ, Juan Carlos. "El Daño". Bogotá: Universidad Externado, 1998

- HINESTROSA FORERO, Fernando. "Tratado de las Obligaciones. Concepto, Estructura y vicisitudes". Tomo I. Tercera edición. Universidad Externado. Bogotá, 2007.

- MAZEAUD, Henri y León, "Tratado de Responsabilidad Civil", Tomo I, Editorial Comlex, México D.F, 1945.

- RODRIGUEZ, ARTURO ALESSANDRI, "DE LA RESPONSABILIDAD EXTRACONTRACTUAL EN EL DERECHO CIVIL", TOMO I, SANTIAGO DE CHILE 1987. EDITORIAL UNIVERSAL.

- TAMAYO JARAMILlO, Javier, "Tratado de Responsabilidad Civil”, Tomo I, BOGOTÁ, 5a ED. EDITORIAL LEGIS, 2010

- TAMAYO JARAMILlO, Javier. "Tratado de responsabilidad civil", Tomo II. Quinta reimpresión. Bogotá: Legis 2010.

- TAMAYO LOMBANA, Alberto. "Manual de las Obligaciones. El acto o negocio jurídico y otras fuentes de obligaciones". Séptima edición, ediciones Doctrina y Ley. Bogotá, 2008.

\section{NORMATIVAS}

- Constitución Política de 1991.

- Ley 769 del 06 de agosto de 2002 "Por la cual se expide el código nacional terrestre y se dictan otras disposiciones".

- Ley 105 del 30 de diciembre de 1993 "Por la cual se dictan disposiciones básicas sobre el transporte, se redistribuyen competencias y recursos entre la Nación y las Entidades Territoriales, se reglamenta la planeación en el sector transporte y se dictan otras disposiciones".
- Ley 1383 del 16 de marzo de 2010 "Por la cual se reforma la Ley 769 de 2002 - Código Nacional de Tránsito, y se dictan otras disposiciones".

- Ley 336 del 20 de diciembre de 1996 "Por la cual se adopta el estatuto nacional de transporte".

- Ley 57 de 1887 "Por la cual se adopta el Código Civil".

- Decreto 01 de 1990 "por la cual se modifica el decreto 410 de 1971".

- Decreto 410 del 27 de marzo 1971 "Por la cual se expide el Código de comercio”.

- Proyecto de acuerdo no. 396 de 2007: "Por el cual se dictan disposiciones relativas a la actividad de los tricimóviles con respecto al tránsito dentro del distrito capital".

- Proyecto de acuerdo no. 526 de 2007"Por el cual se autoriza provisionalmente la circulación de tricimóviles en la ciudad como medio de transporte alternativo"

- Proyecto de acuerdo 260 de 2012"Por medio del cual se ordena la reglamentación de la prestación del servicio de transporte público urbano terrestre no automotor de pasajeros, en el distrito capital".

\section{JURISPRUDENCIALES}

- Sentencia de Casación Civil de $1^{\circ}$ de Junio de 2005.

- Sentencia -210-2004 M.P Jaime Arrubla Paucar.

- Sentencia 033 del 25 de Marzo de 2003. M.P José Fernando Ramirez Gómez.

- CORTE CONSTITUCIONAL, Sentencia C.981 del $1^{\circ}$ de diciembre de 2010, M.P Gabriel Eduardo Mendoza Martelo.

- Consejo de Estado, Sala de Consulta y Servicio Civil, Concepto de 18 de mayo de 2006, Radicación número: 11001-03-06-000-2006-00040-00(1740).

- CORTE CONSTITUCIONAL, Sentencia C-309 de 1997. M.P Alejandro Martínez Caballero.

\section{EN INTERNET}

- http://e.eltiempo.com/media/produccion/ bicitaxis/index.html 